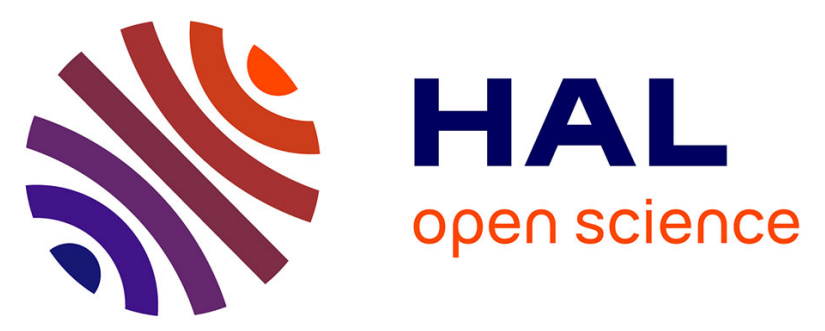

\title{
Three-Dimensional Rotations of the Scapula During Arm Abduction: Evaluation of the Acromion Marker Cluster Method in Comparison With a Model-Based Approach Using Biplanar Radiograph Images
}

Sonia Duprey, Fabien Billuart, Sungjin Sah, Xavier Ohl, Thomas Robert, Wafa Skalli, Xuguang Wang

\section{To cite this version:}

Sonia Duprey, Fabien Billuart, Sungjin Sah, Xavier Ohl, Thomas Robert, et al.. Three-Dimensional Rotations of the Scapula During Arm Abduction: Evaluation of the Acromion Marker Cluster Method in Comparison With a Model-Based Approach Using Biplanar Radiograph Images. Journal of Applied Biomechanics, 2015, 31 (5), pp. 396-402. 10.1123/jab.2014-0244 . hal-01302587

\section{HAL Id: hal-01302587 \\ https://hal.science/hal-01302587}

Submitted on 14 Apr 2016

HAL is a multi-disciplinary open access archive for the deposit and dissemination of scientific research documents, whether they are published or not. The documents may come from teaching and research institutions in France or abroad, or from public or private research centers.
L'archive ouverte pluridisciplinaire HAL, est destinée au dépôt et à la diffusion de documents scientifiques de niveau recherche, publiés ou non, émanant des établissements d'enseignement et de recherche français ou étrangers, des laboratoires publics ou privés. 
"Three-Dimensional Rotations of the Scapula During Arm Abduction: Evaluation of the AMC Method by Comparison With a Model-Based Approach Using Biplanar X-ray" by Duprey S et al.

Note. This article will be published in a forthcoming issue of the Journal of Applied Biomechanics. The article appears here in its accepted, peer-reviewed form, as it was provided by the submitting author. It has not been copyedited, proofread, or formatted by the publisher.

Section: Technical Note

Article Title: Three-Dimensional Rotations of the Scapula During Arm Abduction:

Evaluation of the AMC Method by Comparison With a Model-Based Approach Using Biplanar X-ray

Authors: Sonia Duprey ${ }^{1}$, Fabien Billuart ${ }^{2}$, Sungjin $\mathrm{Sah}^{1}$, Xavier $\mathrm{Ohl}^{2}$, Thomas Robert ${ }^{1}$, Wafa Skalli $^{2}$, and Xuguang Wang ${ }^{1}$

Affiliations: ${ }^{1}$ Laboratoire de Biomécanique et de Mécanique des Chocs UMR_T9406; IFSTTAR, Université de Lyon, Lyon, France. ${ }^{2}$ LBM-Institut de Biomécanique Humaine Georges Charpak, Arts et Métiers ParisTech, Paris, France.

Journal: Journal of Applied Biomechanics

Acceptance Date: June 4, 2015

(C)2015 Human Kinetics, Inc.

DOI: http://dx.doi.org/10.1123/jab.2014-0244 
"Three-Dimensional Rotations of the Scapula During Arm Abduction: Evaluation of the AMC Method by Comparison With a Model-Based Approach Using Biplanar X-ray" by Duprey S et al.

Journal of Applied Biomechanics

(C) 2015 Human Kinetics, Inc.

Three-dimensional rotations of the scapula during arm abduction: evaluation of the AMC method by comparison with a model-based approach using biplanar X-ray images

Sonia Duprey ${ }^{1}$, Fabien Billuart ${ }^{2}$, Sungjin Sah ${ }^{1}$, Xavier Ohl ${ }^{2}$, Thomas Robert ${ }^{1}$, Wafa Skalli ${ }^{2}$, Xuguang Wang ${ }^{1}$

${ }^{1}$ Laboratoire de Biomécanique et de Mécanique des Chocs UMR_T9406; IFSTTAR, F69675 Bron ; Université Claude Bernard Lyon 1, Villeurbanne ; Université de Lyon, F69622, Lyon, France

${ }^{2}$ LBM-Institut de Biomécanique Humaine Georges Charpak, Arts et Métiers ParisTech, 151 Boulevard de 1'Hôpital, 75013 Paris, France

Conflict of interest disclosure: There is no conflict of interest related to this study

\section{Correspondence address:}

Sonia Duprey

LBMC, IFSTTAR

25 Av. F Mitterrand

F-69675 Bron Cedex; FRANCE.

Phone: (+33) 478656882

Fax: (+33) 472142360

Email: sonia.duprey@univ-lyon1.fr 
"Three-Dimensional Rotations of the Scapula During Arm Abduction: Evaluation of the AMC Method by Comparison With a Model-Based Approach Using Biplanar X-ray" by Duprey S et al.

Journal of Applied Biomechanics

(c) 2015 Human Kinetics, Inc.

\begin{abstract}
Non-invasive methods enabling measurement of shoulder bone positions are paramount in clinical and ergonomics applications. In this study, the acromion marker cluster (AMC) method is assessed in comparison to a model-based approach allowing scapula tracking from low dose biplanar X-ray images.
\end{abstract}

Six healthy male subjects participated in this study. Data acquisition was performed for six arm abduction positions $\left(0^{\circ}, 45^{\circ}, 90^{\circ}, 120^{\circ}, 150^{\circ}, 180^{\circ}\right)$. Scapula rotations were calculated using the coordinate systems and angle sequence was defined by the ISB. The comparison analysis was based on RMSE calculation and non-parametric statistical tests.

RMSE remained under $8^{\circ}$ for $0-90^{\circ}$ arm abduction and under $13.5^{\circ}$ for $0-180^{\circ}$ abduction; no significant differences were found between the two methods. Compared to previous works, an improved accuracy of the AMC approach at high arm abduction positions was obtained. This could be explained by the different sources of data used as gold standard.

Keywords: Biomechanics, Kinematics, Motion analysis.

\title{
Abstract word count: 147 words
}

Word count: 1687 words -4 figures (as recommended for a technical note) 
"Three-Dimensional Rotations of the Scapula During Arm Abduction: Evaluation of the AMC Method by Comparison With a Model-Based Approach Using Biplanar X-ray" by Duprey S et al.

Journal of Applied Biomechanics

(C) 2015 Human Kinetics, Inc.

\section{Introduction}

In vivo measurement of scapula orientation remains a major difficulty in the process of upper limb kinematics assessment. Indeed, due to the high amplitude of motion of the shoulder, soft tissue artefacts may strongly affect scapula kinematics measurements made by skin sensors ${ }^{1}$.

Among the in vivo methods that allow measurement of scapula kinematics, the Acromion Marker Cluster (AMC) offers several advantages: beyond being non-invasive, it is easy to carry out and it allows dynamic measurements. This method can either be set up with an electromagnetic system and sensors or with an optoelectronic system and reflective markers: the sensor or a rigid cluster of markers is attached onto the subject's acromion and then the scapula motion is deduced by considering that the acromion cluster and scapula move similarly. This method has been assessed by comparison with palpation ${ }^{2-6}$ or intracortical pins $^{7-8}$. These studies concluded that this method was valid for motion not exceeding $100^{\circ}$ or $120^{\circ}$ of humerus elevation. However, the "gold standards" used to assess the AMC method in these previous works may provide biased results. Palpation has been shown to introduce large discrepancies ${ }^{8-10}$ : the study of Bourne et al. ${ }^{10}$ showed in vivo errors ranging from $2^{\circ}$ to $12.5^{\circ}$ and concluded that palpation at full abduction is not accurate nor reliable; they also noticed that palpation accuracy depends on the skill of the measurer. Also intracortical pins inserted in the bones, in vivo ${ }^{7}$, may affect patients' kinematics by generating discomfort and pain. Therefore, there is a need for further validation of the AMC method using another golden standard.

Several studies ${ }^{11-12}$ have proven that model-based tracking techniques can provide very accurate results for measuring both scapula and humerus motions from biplane radiographic images (inaccuracies of $0.25^{\circ}$ for the scapula ${ }^{11}$ ). Their main disadvantage to the 
"Three-Dimensional Rotations of the Scapula During Arm Abduction: Evaluation of the AMC Method by Comparison With a Model-Based Approach Using Biplanar X-ray" by Duprey S et al.

Journal of Applied Biomechanics

(C) 2015 Human Kinetics, Inc.

patient is the high radiation dose. The $\mathrm{EOS}^{\mathrm{TM}}$ system (EOS Imaging, Paris, France) provides low-dose stereoradiographic X-rays and thus has the advantage of being 6 to 10 times less irradiant than standard X-rays ${ }^{13}$. A model-based method using EOS images has been developed to measure scapula and humerus orientations and positions ${ }^{14-15}$. The accuracy of this model-based approach has been assessed thanks to in vitro data: an average error of $1.3 \mathrm{~mm}$ was found with model reconstruction ${ }^{16}$ and a $2.6^{\circ}$ accuracy could be obtained for scapula orientations ${ }^{17}$.

Thus, the current study aims to compare the AMC method to a model-based method using biplane radiographic images from the $\mathrm{EOS}^{\mathrm{TM}}$ imaging system, in the case of arm abduction positions.

The question considered in this study is: is the AMC method accurate in terms of scapula 3D rotations when compared to this new golden standard (i.e. the model-based approach)?

\section{Methods}

\section{Subjects}

Six healthy male subjects (age: $30.8 \pm 8.5$ years; height: $1.76 \pm 0.08 \mathrm{~m}$; mass: $69 \pm 7.5$ kg) without any history of shoulder pain participated in the study. All the subjects gave informed consent and ethics approval for the study was granted by the French Committee for Person Protection (CPP).

\section{Protocol}

Subjects were asked to randomly perform six arm abduction positions: $0,45,90,120$, 150 and 180 degrees in the frontal plane. An adjustable arm support was used to help the subjects in maintaining the same posture during data acquisition. The arm support was made of an articulated part which enables its extremity to be set in any position; the subjects had to 
"Three-Dimensional Rotations of the Scapula During Arm Abduction: Evaluation of the AMC Method by Comparison With a Model-Based Approach Using Biplanar X-ray" by Duprey S et al.

Journal of Applied Biomechanics

(C) 2015 Human Kinetics, Inc.

hold the arm support extremity with the right hand (Figure 1) while maintaining their feet in the initially recorded positions on the ground.

Subjects were equipped with radiopaque markers placed on their thorax at IJ (Incisura Jugularis), PX (Xiphoid process), C7 (Cerebral vertebrae 7) and T8 (Thoracic vertebrae 8) landmarks. Furthermore, an acromion marker cluster (AMC), a quad-pod equipped with four radiopaque markers, was positioned on the flat part of their acromion, just above the most latero-caudal point, with adhesive tape with the aid of a physical doctor (Figure 1).

Bi-planar X-ray images were obtained thanks to the $\operatorname{EOS}^{\mathrm{TM}}$ system.

\section{Data processing}

Geometric modelling from low-dose biplanar X-rays

A personalised scapula model was reconstructed from the bi-planar X-ray images using a dedicated software (Collaboration between LBM, Paris; LIO, Montreal). The model was created based on the set of X-ray images corresponding to the first posture $\left(0^{\circ}\right.$-humeral elevation); then, a sequence of rigid / elastic deformations was performed to adjust the scapula shape and to assess its position on the set of X-rays corresponding to the subsequent postures [15]. The coordinates of the landmarks required to build the scapula coordinate system (CS) (AA, AI and TS) were extracted from the model.

\section{AMC calibration and method}

Positions of the reflective markers on the thorax, scapula and cluster were located and recorded after identification on the X-ray images. The transformation matrix between the cluster and the scapula CS was defined by the initial set of X-ray images $\left(0^{\circ}\right.$-humeral elevation). This calibration matrix was used to obtain the scapula CS orientation from the cluster CS orientation in the subsequent postures (Eq. 1). 
"Three-Dimensional Rotations of the Scapula During Arm Abduction: Evaluation of the AMC Method by Comparison With a Model-Based Approach Using Biplanar X-ray" by Duprey S et al.

Journal of Applied Biomechanics

(C) 2015 Human Kinetics, Inc.

$$
T_{\text {thorax } \rightarrow \text { scapulapositioni }}=T_{\text {cluster } \rightarrow \text { scapula }}^{\text {calibratio }} \cdot T_{\text {thorax } \rightarrow \text { cluster }, \text { positioni }}
$$

Eq. 1. AMC calibration transformation matrix ( $i$ is the posture index)

A second calibration method based on skin marker positions was also performed in order to provide estimations of potential calibration errors.

Coordinate systems and sequence of rotation angles

Rotations of the scapula were studied in the CS attached to the thorax of each subject. Both scapula and thorax CS were defined as recommended by the $\operatorname{ISB}^{18}$. Euler angles were then calculated from scapula rotation matrices using a Y-X'-Z', sequence.

\section{Data analysis and statistics}

Averages and standard deviations of the rotations were calculated for each of the two methods. Differences and root mean square errors (RMSE) of the rotation angles resulting from the two different methods were evaluated and non-parametric tests (Wilcoxon signed ranked tests) were chosen to assess whether significant differences exist $(\alpha<0.05)$ between the results obtained through the two methods at each elevation angle.

\section{Results}

The AMC method provided accurate results in terms of scapula 3D rotations when compared to the model-based approach considered as golden standard. This result is illustrated in Figures 2-4 (data from Table 1). From a quantitative point of view, relatively small discrepancies were obtained for low arm elevations: less than $8^{\circ}$ for abductions up to $90^{\circ}$ (Table 2). Differences increased up to $13.5^{\circ}$ at higher humeral abduction (Tables 1-2). It can be observed that the AMC method slightly underestimates the upward-downward and antero-posterior rotations for positions above $45^{\circ}$ and $120^{\circ}$ respectively. The signed rank tests performed at each elevation angle did not show any significant differences between the two measurement methods. 
"Three-Dimensional Rotations of the Scapula During Arm Abduction: Evaluation of the AMC Method by Comparison With a Model-Based Approach Using Biplanar X-ray" by Duprey S et al.

Journal of Applied Biomechanics

(C) 2015 Human Kinetics, Inc.

\section{Discussion}

This study provides a comparison of the scapular rotations of six subjects obtained using two in vivo methods: 1) a reference model-based method allowing scapula tracking from low-dose biplanar images and 2) the AMC method. The acromial method has already been assessed as valid by previous studies relying upon palpation or intra-cortical pins as gold standards ${ }^{19}$, but only for moderate arm abductions.

The current results are in agreement with the scapula rotations described in the literature $^{20}$. Furthermore, the current study emphasises the same underestimation of scapular motions recorded with the AMC method as reported by Van Andel et al. ${ }^{3}$. The RMS errors up to $100^{\circ}$ of abduction are in accordance with those reported in the litterature ${ }^{3,4,7,8,19}$; notably Lempereur et al. ${ }^{19}$, in a systematic review, reported errors of $7^{\circ}$ during arm abduction for motions below $100^{\circ}$ of humeral elevation, which is very close to the present results. However, at higher arm abduction, large RMS errors were not found (RMSE up to $13.2^{\circ}$ ) whereas Karduna et al. ${ }^{7}$ and Cereatti et al. ${ }^{8}$ respectively obtained up to $25^{\circ}$ and $44.8^{\circ}$ of error. These discrepancies may be due to the use of different gold standards: the study by Cereatti et al. ${ }^{8}$ included a bias due to the use of post-mortem subjects and as for the study by Karduna et al. ${ }^{7}$, the invasive nature of intra-cortical pins may have hindered subjects' natural motions. These differences may also arise from an underestimation of the current reported errors due to measurements performed in static positions only, whereas literature results ${ }^{7,8}$ are reported for dynamic measurements.

This study has some limitations. The first limitation concerns the calibration of the AMC method. The present results are free from any calibration errors and should be considered with care. Indeed, the transformation matrix between the cluster and scapula CS was obtained using the biplanar X-rays of the $0^{\circ}$-posture, thus it was not possible to compare the scapula rest positions resulting from the two methods, only the evolution of the scapular 
"Three-Dimensional Rotations of the Scapula During Arm Abduction: Evaluation of the AMC Method by Comparison With a Model-Based Approach Using Biplanar X-ray" by Duprey S et al.

Journal of Applied Biomechanics

(C) 2015 Human Kinetics, Inc.

rotations could be compared at different postures. For instance, a calibration based on skin markers could provide discrepancies up to $4^{\circ}$ (see supplementary material). The second limitation concerns the humeral elevation: it was determined using a protractor but was not recalculated using the humerus position recording from the model-based method; these measurements could not be performed since the humerus markers were not visible on all sets of X-rays. However, arm elevation was adjusted to the subjects' height and posture was maintained using an adjustable arm support. The third limitation concerns the small number of subjects: only six healthy adult subjects were tested, while testing also children and pathological adults would have broadened the conclusions. Another limitation concerns the location of the acromion marker cluster: the location at the junction of the scapular spine and the acromion has recently been proven to provide more accurate results ${ }^{21}$ than the location chosen here. This latter location had been chosen in order to replicate other previous protocols $^{2,7}$ and favour comparisons with their results. However it may lower the accuracy of the AMC method. Finally, the last limitation is that only arm abduction static positions were studied due to the low acquisition frequency of the $\operatorname{EOS}^{\mathrm{TM}}$ system; this limits the conclusions since results may be task-specific and velocity-dependant.

In this study, scapular rotations generated by the AMC method were studied. It was shown that few discrepancies exist between the resulting scapula rotations and the rotations generated by a reliable model-based method. In conclusion, the AMC method provides accurate results for low humeral abductions and may also be considered for higher abduction positions.

\section{Acknowledgements}

The authors would like to thank PY Lagacé and N Hagemeister (LIO, Montreal, Canada) for their support. 
"Three-Dimensional Rotations of the Scapula During Arm Abduction: Evaluation of the AMC Method by Comparison With a Model-Based Approach Using Biplanar X-ray" by Duprey S et al.

Journal of Applied Biomechanics

(C) 2015 Human Kinetics, Inc.

\section{References}

1. Matsui K, Shimada K, \& Andrew PD. Deviation of skin marker from bone target during movement of the scapula. J Orthop Sci. 2006; 11(2):180-184.

2. Meskers CGM, Van de Sande MAJ, De Groot JH. Comparison between tripod and skin-fixed recording of scapular motion. J Biomech. 2007; 40(4):941-946.

3. Van Andel C, Van Hutten K, Eversdijk M, et al. Recording scapular motion using an acromion marker cluster. Gait Posture. 2009; 29:123-128.

4. Brochard S, Lempereur M, Rémy-Néris O. Accuracy and reliability of three methods of recording scapular motion using reflective skin markers. Proc. Inst. Mech. Eng. Part H J. Eng. Med. 2011; 225(1):100-105

5. Prinold JAI, Shaheen AF, Bull AMJ. Skin-fixed scapula trackers: A comparison of two dynamic methods across a range of calibration positions. J Biomech. 2011; 44(10): 2004-2007.

6. Warner MB, Chappell PH, Stokes MJ. Measuring scapular kinematics during arm lowering using the acromion marker cluster. Hum Movement Sci. 2012; 31(2):386396.

7. Karduna AR, McClure PW, Michener LA, Sennett B. Dynamic measurements of three-dimensional scapular kinematics: A validation study. J Biomech Eng. 2001; 123:184-190.

8. Cereatti A, Rosso C, Nazarian A, et al. Scapular Motion Tracking Using Acromion Skin Marker Cluster: In Vitro Accuracy Assessment. J Med Biol Eng. 2015; 1-10. doi:10.1007/s40846-015-0010-2

9. Moriguchi CS, Carnaz L, Silva LCCB, et al. Reliability of intra-and inter-rater palpation discrepancy and estimation of its effects on joint angle measurements. Manual Ther. 2009; 14(3):299-305.

10. Bourne D, Choo A, Regan W, et al. Accuracy of digitization of bony landmarks for measuring change in scapular attitude. Proc. Inst. Mech. Eng. Part H J. Eng. Med. 2009; 223(3):349-361.

11. Bey MJ, Kline SK, Zauel R, et al. Validation of a new model-based tracking technique for measuring three-dimensional, in vivo glenohumeral joint kinematics. $J$ Biomech Eng. 2006; 128(4):604-609.

12. Nishinaka N, Tsutsui H, Mihara K, et al. Determination of in vivo glenohumeral translation using fluoroscopy and shape-matching techniques. J Shoulder Elbow Surg. 2008; 17(2):319-322.

13. Dubousset J, Charpak G, Skalli W, et al. EOS stereo-radiography system: whole-body simultaneous anteroposterior and lateral radiographs with very low radiation dose. Rev Chir Orthop Reparatrice Appar Mot. 2007; 93(6 Suppl):141-3. 
"Three-Dimensional Rotations of the Scapula During Arm Abduction: Evaluation of the AMC Method by Comparison With a Model-Based Approach Using Biplanar X-ray" by Duprey S et al.

Journal of Applied Biomechanics

(C) 2015 Human Kinetics, Inc.

14. Ohl X, Billuart F, Lagacé PY, et al. 3D morphometric analysis of 43 scapulae. Surg Radiol Anat. 2012; 34(5):447-53.

15. Lagacé PY, Billuart F, Ohl X, et al. Analysis of humeral head displacements from sequences of biplanar X-rays: repeatability study and preliminary results in healthy subjects. Comput Methods Biomech Biomed Engin. 2012; 15(3):221-229. doi:10.1080/10255842.2010.522185

16. Lagacé PY, Cresson T, Hagemeister N, et al. 3D Reconstruction of the Scapula from Biplanar Radiographs. Paper presented at: Proceedings of SPIE; 23 February, 2012; San Diego, California. doi:10.1117/12.911527

17. Duprey S, Lagacé PY, Cresson T, et al. Assessment of a model-based method for scapula kinematics measurement. Paper presented at: $1^{\text {st }}$ Clinical Movement Analysis World Conference; 1-5 oct 2014; Rome, Italy.

18. Wu G, van der Helm FCT, Veeger HEJ, et al. ISB recommendation on definitions of joint coordinate systems of various joints for the reporting of human joint motionPart II: shoulder, elbow, wrist and hand. J Biomech. 2005; 38:981-992.

19. Lempereur M, Brochard S, Leboeuf $\mathrm{F}$ et al. Validity and reliability of 3D marker based scapular motion analysis: A systematic review. J Biomech. 2014;47(10):22192230.

20. Ludewig PM, Phadke V, Braman JP, et al. Motion of the shoulder complex during multiplanar humeral elevation. J Bone Joint Surg. 2009; 91(2):378-389.

21. Shaheen AF, Alexander CM, Bull AMJ. Effects of attachment position and shoulder orientation during calibration on the accuracy of the acromial tracker. $J$ Biomech. 2011;44.(7):1410-1413. 
"Three-Dimensional Rotations of the Scapula During Arm Abduction: Evaluation of the AMC Method by Comparison With a Model-Based Approach Using Biplanar X-ray" by Duprey S et al.

Journal of Applied Biomechanics

(C) 2015 Human Kinetics, Inc.

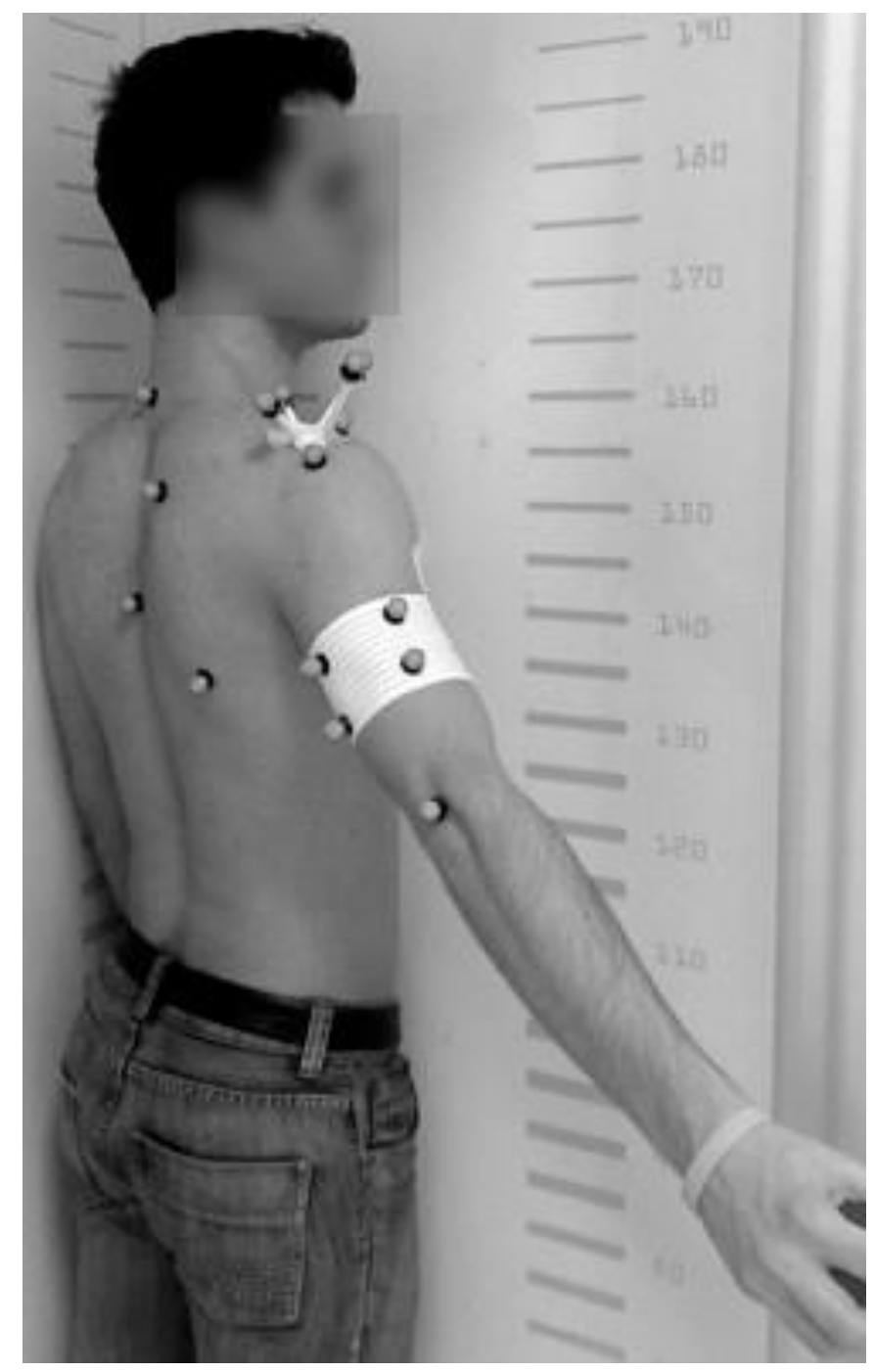

Figure 1. A subject equipped with markers and acromion marker cluster (AMC), posing in the cabin dedicated to low-dose bi-planar X-ray measurements. 


\section{Upward-downward rotation}

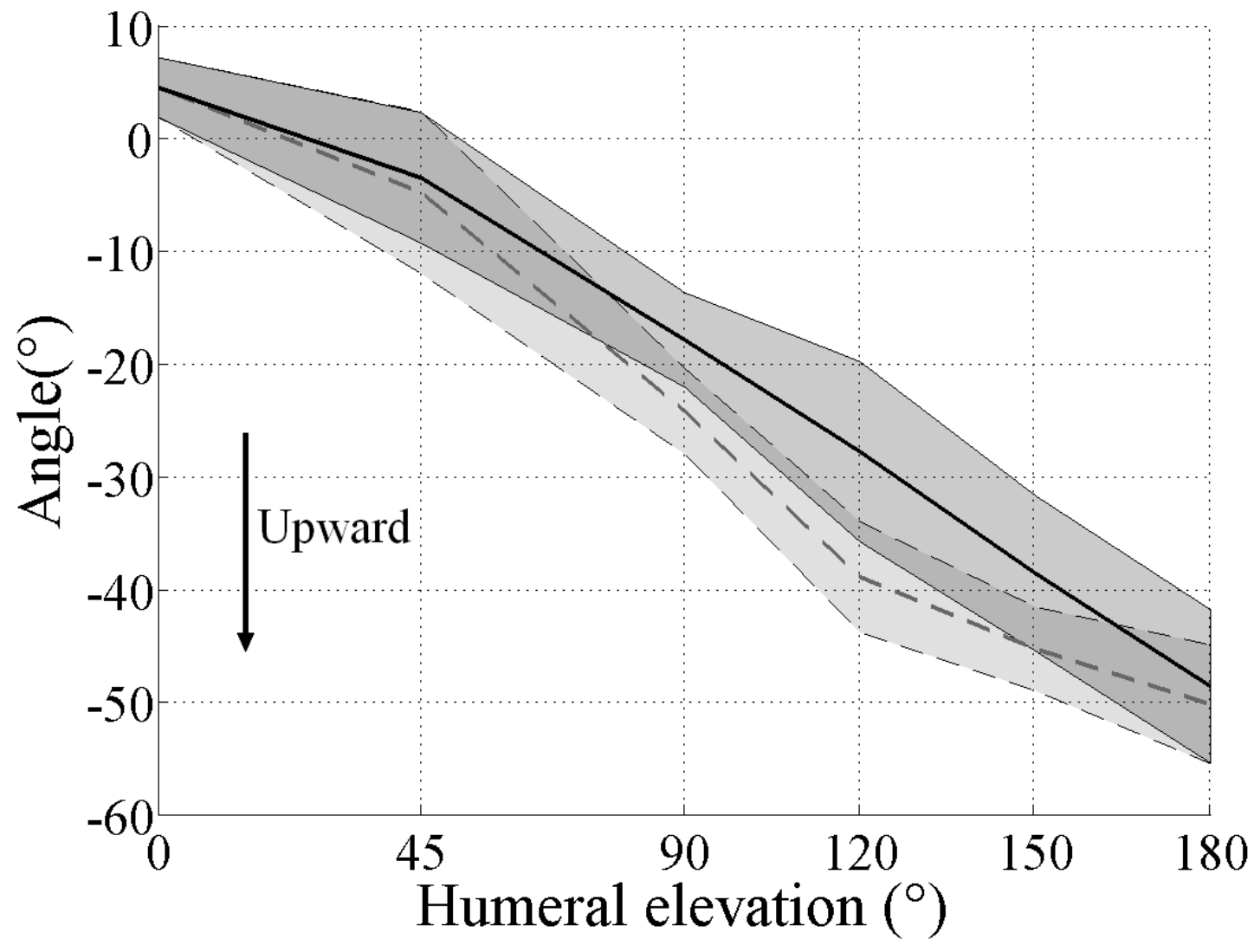

Figure 2. Scapula upward-downward rotation versus humeral abduction. The model-based approach is illustrated in pale grey color (average and standard deviations are plotted as dashed lines), the AMC approach is illustrated in dark grey color (average and standard deviations are plotted as full lines). 


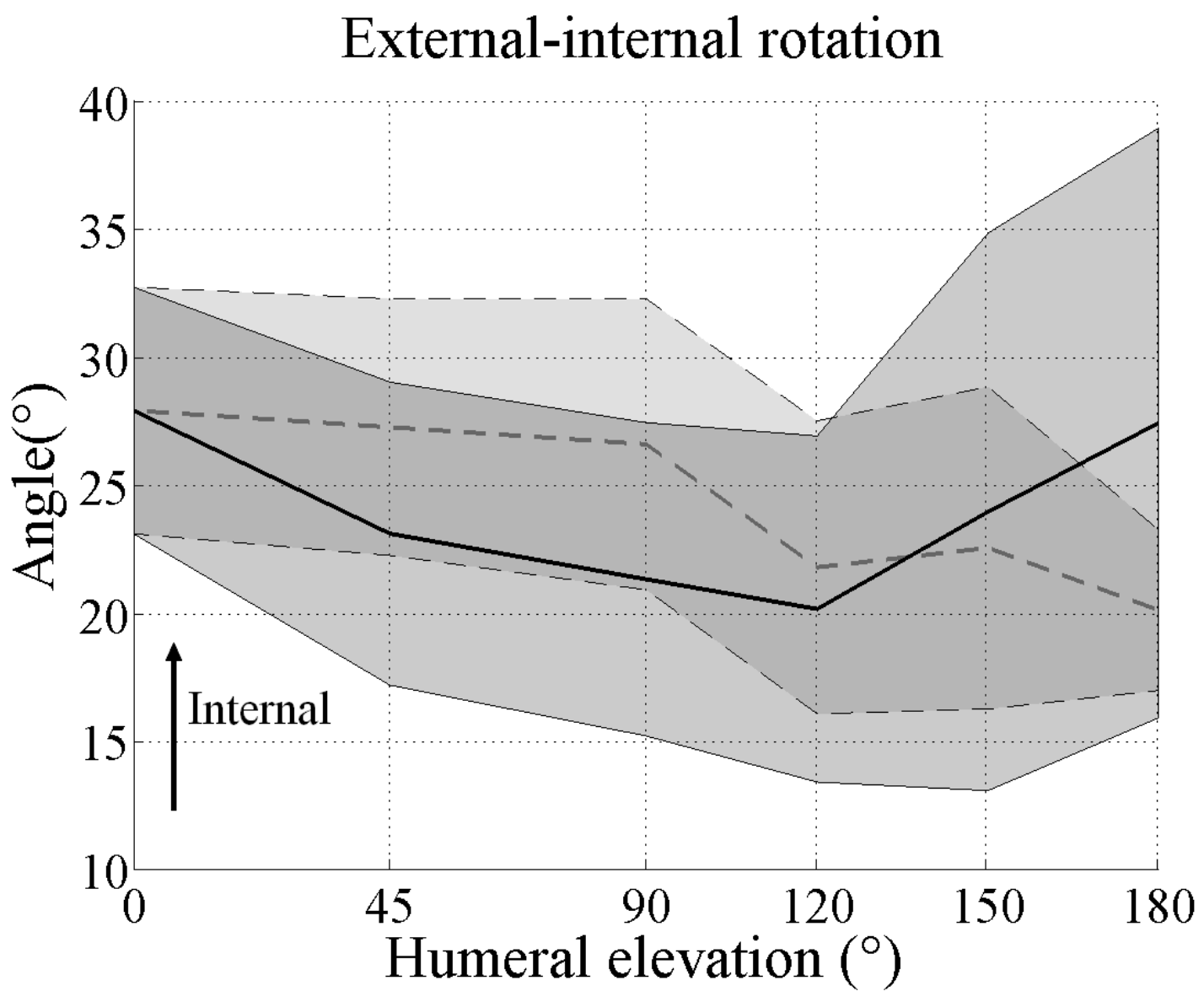

Figure 3. Scapula external-internal rotation versus humeral abduction. The model-based approach is illustrated in pale grey color (average and standard deviations are plotted as dashed lines), the AMC approach is illustrated in dark grey color (average and standard deviations are plotted as full lines). 


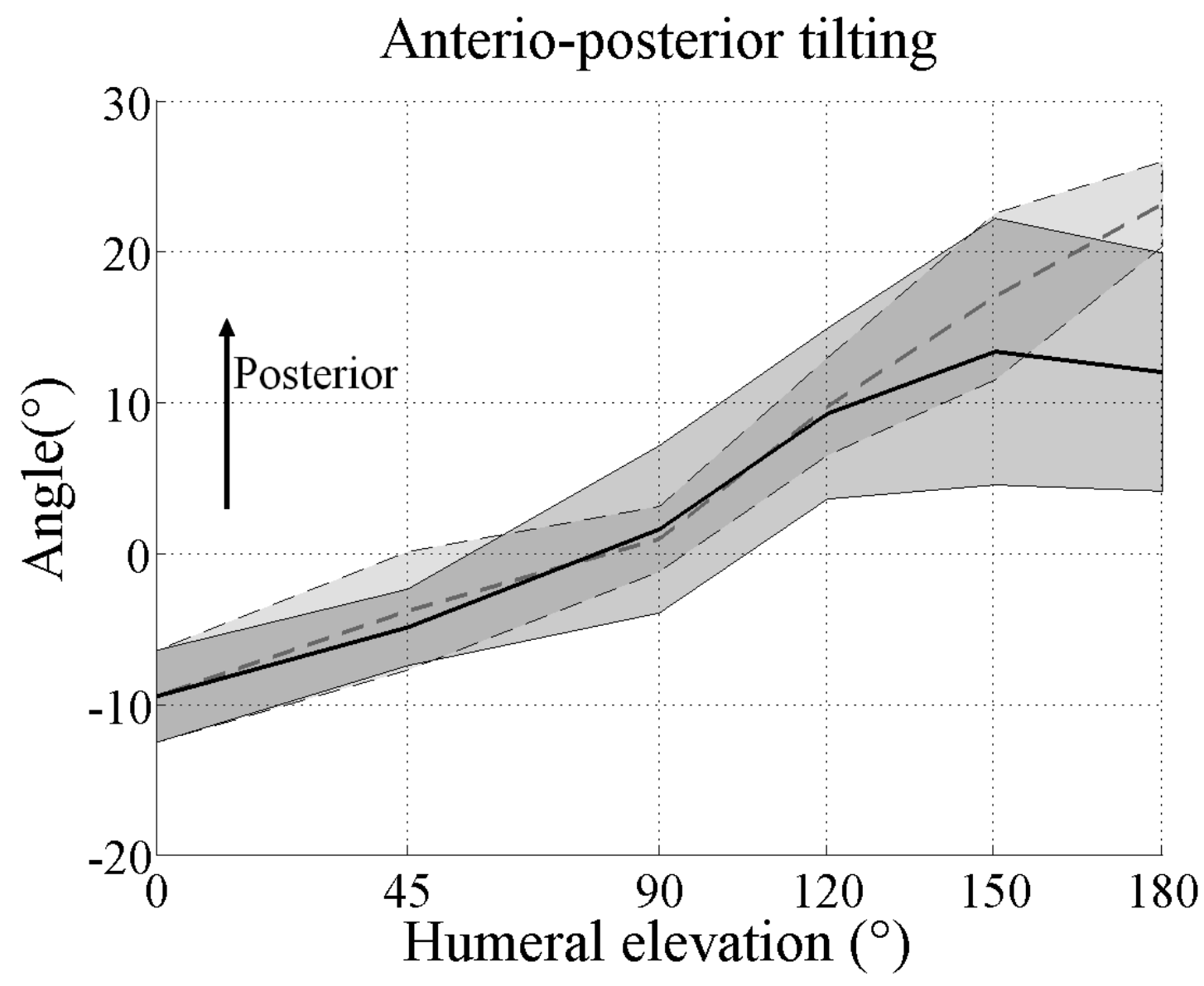

Figure 4. Scapula external-internal rotation versus humeral abduction. The model-based approach is illustrated in pale grey color (average and standard deviations are plotted as dashed lines), the AMC approach is illustrated in dark grey color (average and standard deviations are plotted as full lines). 
"Three-Dimensional Rotations of the Scapula During Arm Abduction: Evaluation of the AMC Method by Comparison With a Model-Based Approach Using Biplanar X-ray" by Duprey S et al.

Journal of Applied Biomechanics

(C) 2015 Human Kinetics, Inc.

Table 1. The three scapula rotations for the two measurement methods during humeral abduction.

\begin{tabular}{|c|c|c|c|c|c|c|}
\hline & \multicolumn{2}{|c|}{ Upward-downward rotation $\left(^{\circ}\right)$} & \multicolumn{2}{|c|}{ External-internal rotation $\left(^{\circ}\right)$} & \multicolumn{2}{c|}{ Anterior-posterior tilting $\left(^{\circ}\right)$} \\
\hline & Model based & AMC & Model based & AMC & Model based & AMC \\
\hline $0^{\circ}$ & $4.5 \pm 2.6$ & $4.5 \pm 2.6$ & $27.9 \pm 4.8$ & $27.9 \pm 4.8$ & $-9.5 \pm 3.0$ & $-9.5 \pm 3.0$ \\
\hline $45^{\circ}$ & $-4.8 \pm 7.2$ & $-3.3 \pm 5.9$ & $27.2 \pm 5.0$ & $23.1 \pm 5.9$ & $-3.8 \pm 3.9$ & $-4.9 \pm 2.6$ \\
\hline $90^{\circ}$ & $-24.2 \pm 3.8$ & $-17.7 \pm 4.3$ & $26.6 \pm 5.7$ & $21.3 \pm 6.1$ & $0.9 \pm 3.2$ & $1.5 \pm 5.5$ \\
\hline $120^{\circ}$ & $-38.9 \pm 4.9$ & $-27.6 \pm 8.0$ & $21.8 \pm 5.7$ & $20.2 \pm 6.7$ & $9.7 \pm 3.2$ & $9.2 \pm 5.7$ \\
\hline $150^{\circ}$ & $-45.2 \pm 3.7$ & $-38.4 \pm 7.0$ & $22.5 \pm 6.3$ & $24.0 \pm 10.8$ & $17.0 \pm 5.5$ & $13.3 \pm 8.9$ \\
\hline $180^{\circ}$ & $-50.1 \pm 5.3$ & $-48.4 \pm 7.0$ & $20.1 \pm 3.1$ & $27.5 \pm 11.5$ & $23.1 \pm 2.8$ & $11.9 \pm 7.9$ \\
\hline
\end{tabular}

Table 2. RMSE and differences (average \pm standard deviations) for the AMC method compared to the model-based method as gold standard for the three scapula rotations.

\begin{tabular}{|c|c|c|c|c|c|c|}
\hline & \multicolumn{2}{|c|}{ Upward-downward rotation $\left(^{\circ}\right)$} & \multicolumn{2}{l|}{ External-internal rotation $\left(^{\circ}\right)$} & \multicolumn{2}{c|}{ Anterior-posterior tilting $\left(^{\circ}\right)$} \\
\hline & RMSE & Differences & RMSE & Differences & RMSE & Differences \\
\hline $45^{\circ}$ & $\mathbf{3 . 0}$ & $-0.7 \pm 1.4$ & $\mathbf{6 . 9}$ & $5.1 \pm 6.5$ & $\mathbf{2 . 1}$ & $1.2 \pm 1.8$ \\
\hline $90^{\circ}$ & $\mathbf{8 . 1}$ & $-7.0 \pm 5.1$ & $\mathbf{7 . 5}$ & $5.9 \pm 6.0$ & $\mathbf{4 . 1}$ & $0.0 \pm 4.1$ \\
\hline $120^{\circ}$ & $\mathbf{1 3 . 5}$ & $-12.4 \pm 7.1$ & $\mathbf{6 . 9}$ & $2.4 \pm 7.3$ & $\mathbf{3 . 5}$ & $1.2 \pm 3.7$ \\
\hline $150^{\circ}$ & $\mathbf{1 0 . 5}$ & $-8.4 \pm 8.0$ & $\mathbf{9 . 3}$ & $-1.8 \pm 9.0$ & $\mathbf{7 . 1}$ & $5.4 \pm 6.9$ \\
\hline $180^{\circ}$ & $\mathbf{9 . 4}$ & $-4.2 \pm 9.6$ & $\mathbf{1 2 . 9}$ & $-7.9 \pm 10.3$ & $\mathbf{1 2 . 9}$ & $12.9 \pm 6.7$ \\
\hline
\end{tabular}


"Three-Dimensional Rotations of the Scapula During Arm Abduction: Evaluation of the AMC Method by Comparison With a Model-Based Approach Using Biplanar X-ray" by Duprey S et al.

Journal of Applied Biomechanics

(C) 2015 Human Kinetics, Inc.

\section{SUPPLEMENTARY MATERIAL: Specific data for each subject}

Supplementary Table 1: Scapula rotations for the two measurement methods during humeral abduction for Subject 1

\begin{tabular}{|c|c|c|c|c|c|c|}
\hline & \multicolumn{2}{|c|}{ Upward-downward rotation $\left(^{\circ}\right)$} & \multicolumn{2}{c|}{ External-internal rotation $\left(^{\circ}\right)$} & \multicolumn{2}{c|}{ Anterior-posterior tilting $\left(^{\circ}\right)$} \\
\hline & Model based & AMC & Model based & AMC & Model based & AMC \\
\hline $0^{\circ}$ & 8,1 & 8,1 & 21,1 & 21,1 & $-7,8$ & $-7,8$ \\
\hline $45^{\circ}$ & $-7,3$ & $-9,2$ & 19,7 & 13,0 & 0,9 & $-1,1$ \\
\hline $90^{\circ}$ & $-20,5$ & $-24,2$ & 21,3 & 12,2 & 4,5 & 5,8 \\
\hline $120^{\circ}$ & $-34,1$ & $-37,1$ & 17,1 & 9,8 & 12,4 & 13,8 \\
\hline $150^{\circ}$ & $-43,1$ & $-50,8$ & 15,9 & 7,5 & 21,2 & 22,1 \\
\hline $180^{\circ}$ & $-43,0$ & $-57,6$ & 19,4 & 9,9 & 23,7 & 24,7 \\
\hline
\end{tabular}

Supplementary Table 2: Scapula rotations for the two measurement methods during humeral abduction for Subject 2

\begin{tabular}{|c|c|c|c|c|c|c|}
\hline & \multicolumn{2}{|c|}{ Upward-downward rotation $\left(^{\circ}\right)$} & \multicolumn{2}{c|}{ External-internal rotation $\left(^{\circ}\right)$} & \multicolumn{2}{c|}{ Anterior-posterior tilting $\left(^{\circ}\right)$} \\
\hline & Model based & AMC & Model based & AMC & Model based & AMC \\
\hline $0^{\circ}$ & 4,3 & 4,3 & 28,2 & 28,2 & $-9,4$ & $-9,4$ \\
\hline $45^{\circ}$ & 4,5 & 5,6 & 27,9 & 30,0 & $-8,6$ & $-7,4$ \\
\hline $90^{\circ}$ & $-18,0$ & $-11,8$ & 17,6 & 18,5 & $-2,8$ & $-10,0$ \\
\hline $120^{\circ}$ & $-31,3$ & $-12,9$ & 17,5 & 16,9 & 5,0 & $-0,2$ \\
\hline $150^{\circ}$ & $-39,0$ & $-33,5$ & 18,7 & 26,3 & 11,1 & 3,7 \\
\hline $180^{\circ}$ & $-45,2$ & $-46,4$ & 21,8 & 34,0 & 20,8 & 3,4 \\
\hline
\end{tabular}

Supplementary Table 3: Scapula rotations for the two measurement methods during humeral abduction for Subject 3

\begin{tabular}{|c|c|c|c|c|c|c|}
\hline & \multicolumn{2}{|c|}{ Upward-downward rotation $\left(^{\circ}\right)$} & \multicolumn{2}{|c|}{ External-internal rotation $\left(^{\circ}\right)$} & \multicolumn{2}{c|}{ Anterior-posterior tilting $\left(^{\circ}\right)$} \\
\hline & Model based & AMC & Model based & AMC & Model based & AMC \\
\hline $0^{\circ}$ & 1,2 & 1,2 & 33,1 & 33,1 & $-3,8$ & $-3,8$ \\
\hline $45^{\circ}$ & $-0,7$ & $-0,9$ & 32,0 & 29,9 & 0,6 & $-3,5$ \\
\hline $90^{\circ}$ & $-26,0$ & $-17,7$ & 28,1 & 26,2 & 1,1 & 4,9 \\
\hline $120^{\circ}$ & $-43,5$ & $-27,1$ & 15,8 & 21,1 & 8,6 & 13,9 \\
\hline $150^{\circ}$ & $-49,9$ & $-32,2$ & 18,4 & 22,6 & 15,9 & 21,8 \\
\hline $180^{\circ}$ & $-58,6$ & $-47,1$ & 17,0 & 32,2 & 18,9 & 6,7 \\
\hline
\end{tabular}

Supplementary Table 4: Scapula rotations for the two measurement methods during humeral abduction for Subject 4

\begin{tabular}{|c|c|c|c|c|c|c|}
\hline & \multicolumn{2}{|c|}{ Upward-downward rotation $\left(^{\circ}\right)$} & \multicolumn{2}{c|}{ External-internal rotation $\left(^{\circ}\right)$} & \multicolumn{2}{c|}{ Anterior-posterior tilting $\left(^{\circ}\right)$} \\
\hline & Model based & AMC & Model based & AMC & Model based & AMC \\
\hline $0^{\circ}$ & 2,7 & 2,7 & 22,0 & 22,0 & $-10,7$ & $-10,7$ \\
\hline $45^{\circ}$ & $-5,2$ & $-3,9$ & 21,5 & 23,8 & $-8,2$ & $-7,4$ \\
\hline $90^{\circ}$ & $-27,6$ & $-15,7$ & 28,2 & 29,0 & 0,2 & 5,4 \\
\hline $120^{\circ}$ & $-44,0$ & $-28,6$ & 22,1 & 30,6 & 14,9 & 14,4 \\
\hline $150^{\circ}$ & $-48,9$ & $-39,1$ & 25,7 & 43,0 & 27,0 & 21,3 \\
\hline $180^{\circ}$ & $-52,2$ & $-46,0$ & 22,7 & 45,6 & 25,7 & 13,2 \\
\hline
\end{tabular}


"Three-Dimensional Rotations of the Scapula During Arm Abduction: Evaluation of the AMC Method by Comparison With a Model-Based Approach Using Biplanar X-ray" by Duprey S et al.

Journal of Applied Biomechanics

(C) 2015 Human Kinetics, Inc.

Supplementary Table 5: Scapula rotations for the two measurement methods during humeral abduction for Subject 5

\begin{tabular}{|c|c|c|c|c|c|c|}
\hline & \multicolumn{2}{|c|}{ Upward-downward rotation $\left(^{\circ}\right)$} & \multicolumn{2}{|c|}{ External-internal rotation $\left(^{\circ}\right)$} & \multicolumn{2}{c|}{ Anterior-posterior tilting $\left(^{\circ}\right)$} \\
\hline & Model based & AMC & Model based & AMC & Model based & AMC \\
\hline $0^{\circ}$ & 7,9 & 7,9 & 32,8 & 32,8 & $-12,6$ & $-12,6$ \\
\hline $45^{\circ}$ & $-1,7$ & 0,3 & 32,7 & 19,4 & $-5,7$ & $-7,4$ \\
\hline $90^{\circ}$ & $-24,4$ & $-14,7$ & 29,2 & 16,2 & 1,5 & $-0,0$ \\
\hline $120^{\circ}$ & $-37,6$ & $-23,9$ & 27,0 & 16,9 & 7,3 & 3,2 \\
\hline $150^{\circ}$ & $-43,7$ & $-31,2$ & 21,8 & 16,8 & 13,7 & 0,7 \\
\hline $180^{\circ}$ & $-48,3$ & $-36,6$ & 15,5 & 18,89 & 22,3 & 4,2 \\
\hline
\end{tabular}

Supplementary Table 6: Scapula rotations for the two measurement methods during humeral abduction for Subject 6

\begin{tabular}{|c|c|c|c|c|c|c|}
\hline & \multicolumn{2}{|c|}{ Upward-downward rotation $\left(^{\circ}\right)$} & \multicolumn{2}{c|}{ External-internal rotation $\left(^{\circ}\right)$} & \multicolumn{2}{c|}{ Anterior-posterior tilting $\left(^{\circ}\right)$} \\
\hline & Model based & AMC & Model based & AMC & Model based & AMC \\
\hline $0^{\circ}$ & 2,6 & 2,6 & 30,3 & 30,3 & $-12,6$ & $-12,6$ \\
\hline $45^{\circ}$ & $-18,6$ & $-11,9$ & 29,8 & 22,4 & $-1,7$ & $-2,8$ \\
\hline $90^{\circ}$ & $-28,6$ & $-22,2$ & 35,1 & 25,9 & 1,2 & 3,3 \\
\hline $120^{\circ}$ & $-42,7$ & $-35,8$ & 31,3 & 25,9 & 10,0 & 9,9 \\
\hline $150^{\circ}$ & $-46,8$ & $-43,6$ & 34,8 & 27,6 & 12,9 & 10,2 \\
\hline $180^{\circ}$ & $-53,5$ & $-56,6$ & 24,3 & 24,2 & 27,2 & 19,3 \\
\hline
\end{tabular}

\section{SUPPLEMENTARY MATERIAL: Calibration error}

Supplementary Table 7: Scapula rotations obtained by two different calibration methods (1/ an ideal calibration based on biplanar X-rays measurements, 2/ a calibration based on skin marker positions measurements) and mean calibration errors.

\begin{tabular}{|c|c|c|c|c|c|c|}
\hline & \multicolumn{2}{|c|}{ Upward-downward rotation $\left(^{\circ}\right)$} & \multicolumn{2}{c|}{ External-internal rotation $\left(^{\circ}\right)$} & \multicolumn{2}{c|}{ Anterior-posterior tilting $\left(^{\circ}\right)$} \\
\hline & $\begin{array}{c}\text { Ideal } \\
\text { Calibration }\end{array}$ & $\begin{array}{c}\text { Calibration } \\
\text { from SkM }\end{array}$ & $\begin{array}{c}\text { Ideal } \\
\text { Calibration }\end{array}$ & $\begin{array}{c}\text { Calibration } \\
\text { from SkM }\end{array}$ & $\begin{array}{c}\text { Ideal } \\
\text { Calibration }\end{array}$ & $\begin{array}{c}\text { Calibration } \\
\text { from SkM }\end{array}$ \\
\hline $0^{\circ}$ & 4.5 & 3.2 & 27.9 & 29.0 & -9.5 & -13.0 \\
\hline $45^{\circ}$ & -3.3 & -4.7 & 23.1 & 24.2 & -4.9 & -8.7 \\
\hline $90^{\circ}$ & -17.7 & -19.3 & 21.3 & 22.4 & 1.5 & -2.4 \\
\hline $120^{\circ}$ & -27.6 & -29.2 & 20.2 & 21.2 & 9.2 & 5.0 \\
\hline $150^{\circ}$ & -38.4 & -40.0 & 24.0 & 24.9 & 13.3 & 9.0 \\
\hline $180^{\circ}$ & -48.4 & -50.1 & 27.5 & 28.8 & 11.9 & 7.3 \\
\hline Mean Error & \multicolumn{2}{|c|}{$1.5^{\circ} \pm 0.2^{\circ}$} & \multicolumn{2}{c|}{$-1.1^{\circ} \pm 0.1^{\circ}$} & & $4^{\circ} \pm 0.4^{\circ}$ \\
\hline
\end{tabular}

